https://doi.org/10.7203/Normas.4.4690

\title{
REFLEXIONES EN TORNO AL GÉNERO BOLETÍN DIGITAL TURÍSTICO: SITUACIÓN COMUNICATIVA Y ANÁLISIS LINGÜÍSTICO
}

\author{
REFLECTIONS ON THE CYBERGENRE TOURISTIC NEWSLETTER: \\ COMMUNICATIVE SITUATION AND LINGUISTIC ANALYSIS
}

\author{
Rosa María RoDRíGUEZ ABELlA \\ Università degli Studi di Verona
}

\section{RESUMEN:}

La newsletter es una estrategia de web marketing muy utilizada en la actualidad por empresas e instituciones de todo tipo. De hecho, se trata de un género nuevo y emergente de Internet (Shepherd y Watters, 1998: 98), cuyo principal propósito comunicativo es la persuasión directa de los suscriptores. En el presente estudio nos proponemos determinar las principales características de este género discursivo, utilizando como corpus de referencia las últimas 27 newsletter del portal Spain.info.

PALABRAS CLAVE: comunicación turística, boletín digital turístico, géneros digitales, lingüística de corpus, estrategías lingüísticas.

\section{ABSTRACT:}

The newsletter is a web marketing strategy currently used by most companies and institutions of all kinds. In fact, this is a novel genre of Internet, an emergent genre (Shepherd and Watters, 1998: 98), whose main communicative purpose is the direct persuasion of subscribers. In the present study, using a corpus of the last 27 Spain.info newsletters, we propose to determine the main characteristics of this communicative discourse genre.

KEY WORDS: tourism communication, touristic newsletter, cybergenres, corpus linguistics, linguistic strategies. 
El turista ha evolucionado hacia un perfil más exigente y crítico, donde el uso de Internet y las redes sociales le permiten acceder a una gran cantidad de información y opiniones sobre los destinos turísticos, lo que le posiciona con un mayor poder de decisión.

(Plan Nacional e Integral de Turismo 2012-2015: 23) ${ }^{1}$

\section{INTRODUCCIÓN}

No cabe duda de que en los últimos años estamos asistiendo a una profunda transformación de los turistas y de sus comportamientos. El uso de las redes sociales y el consiguiente «boca-oreja digital» han cambiando las reglas del juego, de modo que los turistas han dejado de ser simples consumidores y han pasado a convertirse en protagonistas que utilizan la red para planear o adaptar a su conveniencia el producto turístico. En este contexto, la newsletter se erige en una estrategia de web marketing muy utilizada por empresas e instituciones de todo tipo, con el objetivo de conservar y fidelizar al mayor número posible de consumidores o, en el caso que nos ocupa, de potenciales turistas ${ }^{2}$. En el presente estudio nos planteamos determinar las convenciones estructurales y textuales prototípicas del género newsletter institucional de promoción turística. Para ello, en primer lugar, ilustraremos sucintamente los principales rasgos distintivos de dicho género. A continuación, utilizando como corpus de estudio las últimas 27 newsletter de Spain.info, analizaremos los rasgos lingüísticos más frecuentes que aparecen en estos textos: la elección de tiempos y formas verbales, el modo, los rasgos léxicos, etc.

\section{MARKETING ONLINE Y TURISMO}

El 25 de junio de 2013, Spain.info cumplía once años de existencia ${ }^{3}$. De hecho, el portal constituye un excelente testimonio de la labor de promoción turística que viene desarrollando el Estado a través de Internet. Obviamente, a nadie se le escapa que el turismo es un sector fundamental para la economía española. Efectivamente, como apuntaba recientemente José Manuel Soria (PNIT 2012-2015: 3), ministro de Industria, Energía y Turismo,

España tiene el liderazgo mundial en turismo. Somos el primer destino del mundo en turismo vacacional, el segundo país por gasto turístico y el cuarto por el número de

${ }^{1}$ El Plan Nacional e Integral de Turismo 2012-2015 se puede consultar en www.tourspain.es.

${ }^{2}$ Entre las principales herramientas de web marketing, aparte de las newsletters, cabe destacar los sitios o portales web empresariales, los blogs, los e-mail marketing, etc. Sobre el web marketing, véase Pini (2010: 93-119).

${ }^{3}$ El portal se lanzó en junio de 2002, aunque cabe recordar que Turespaña ya había lanzado anteriormente un sito web, www.tourspain.es, exactamente el 1 de enero de 1998. 
turistas. La actividad turística supone más de un $10 \%$ del PIB, crea un $11 \%$ del empleo y contrarresta en gran medida nuestro déficit comercial.

El ministro Soria, coincidiendo con este décimo primer aniversario de Spain.info, anunciaba también que, con el objetivo de dar respuesta al turista digital, el portal turístico gestionado por Segittur iniciaba una nueva etapa como comercializador ${ }^{4}$. Esta decisión viene a confirmar algo que ya se intuía desde hace tiempo, esto es, que la tecnología digital estará unida, cada vez más, a todas las fases de consumo del producto turístico. Efectivamente, según el Instituto de Turismo de España,

el $80 \%$ de los turistas que visitan España son usuarios de Internet, seis de cada diez búsquedas en la red están relacionadas con viajes y destinos y el $40 \%$ del comercio electrónico corresponde a la venta de productos turísticos ${ }^{5}$.

Las cifras son elocuentes; por tanto, parece lógico que Turespaña trate de reforzar cada día más su presencia en el mundo digital ${ }^{6}$. De hecho, en el caso de la campaña online, la nueva estrategia diseñada con el objetivo de reposicionar España a través de la innovación y el desarrollo tecnológico apuesta, sobre todo, por las redes sociales y las aplicaciones móviles ${ }^{7}$, con el objetivo de interactuar de forma más cercana con el turista. Porque, ciertamente,

el turista ha cambiado la forma de organizar su viaje. Primero se inspira en las vivencias de otros viajeros, busca información, consulta opiniones y posteriormente reserva su viaje, durante el cual comparte su experiencia con otros usuarios a través de las redes sociales. (Segittur-Proyectos, 2013).

Por lo tanto, el turista se sitúa ahora en el centro de todo el proceso informativo, porque la información se genera en tiempo real y se comparte en redes sociales. En esta óptica del turista como sujeto activo, la newsletter se erige en una herramienta de web marketing muy útil para los destinos turísticos ${ }^{8}$. En efecto, gracias a este instrumento, los destinos establecen un vínculo directo con los potenciales clientes, instaurándose

${ }^{4}$ Se señala también que Spain.info no se ocupará de las reservas, sino que las derivará a la página web de los proveedores. El turista encontrará un comparador para cada producto. Una opción que desde Turespaña creen que es la más transparente y la que permite dar cabida a un mayor número de alojamientos turísticos, unos 20000 . Sobre este y otros aspectos novedosos del portal, véase www.hosteltur.com.

${ }^{5}$ Véase la sección marketing on line en www.tourspain.es [Consulta: 10/11/ 2013].

${ }^{6}$ Otros desarrollos previstos en el mundo digital comprenden aplicaciones móviles para iPad y iPhone, presencia en el canal temático YouTube y la línea de audiovisuales de España, todo encaminado a que el destino España llegue progresivamente a un mayor número de turistas potenciales.

${ }^{7}$ En concreto, en el caso de la campaña online se utilizará gráfica, integración de contenidos, $e$ mail marketing y enlaces patrocinados. Para más información, véase la sección Proyectos de www.segittur.es.

${ }^{8}$ De manera simplificada, concebimos la newsletter como un boletín electrónico que se recibe de forma periódica en texto plano o en código html y que contiene información relevante para el receptor. 
casi una relación one-to-one, porque el destinatario recibe la newsletter en su buzón de correo electrónico.

\section{EL CIBERGÉNERO NEWSLETTER. ELEMENTOS ESTRUCTURALES CARACTERIZANTES}

No obstante el intrínseco dinamismo y la versatilidad que caracteriza el mundo digital, diferentes estudios (Santini, 2007) han demostrado que también en un entorno web los usuarios son conscientes de lo que es un género. Por lo tanto, asocian formas estandarizadas diferentes con géneros diversos. Nosotros, de acuerdo con Erickson (citado en Paolillo, Warren y Kunz, 2010: 278), concebimos el género como

a patterning of communication created by a combination of the individual, social and technical forces implicit in a recurring communicative situation. A genre structures communication by creating shared expectations about the form and content of the interaction, thus easing the burden of production and interpretation.

Ahora bien, como ponen de relieve Shephred y Watters (1998), el entorno digital, por una parte, ha determinado la transformación de algunos géneros ya existentes dando lugar a los géneros réplica y a los variantes ${ }^{9}$. Por otra parte, Internet ha propiciado también el nacimiento de géneros nuevos, emergentes y espontáneos ${ }^{10}$.

Por lo que se refiere a la newsletter, en realidad, esta es fruto de la evolución digital de un género tradicional, en concreto, del popular boletín informativo, que aún hoy en día se sigue divulgando en papel. El boletín, al instalarse en la red, se ha ido adaptando paulatinamente al nuevo medio, y ha evolucionado tanto que actualmente se puede considerar ya un género nuevo ${ }^{11}$. Por tanto, si nos basamos en la ya clásica taxonomía de géneros cibernéticos de Shepherd y Watters (1998: 98), la newsletter se puede considerar un género digital nuevo emergente. Hoy en día, el boletín digital presenta una estructura bastante estable de los elementos del discurso. En realidad, nos hallamos ante un género muy instituzionalizado, con una tradición y macroestructura bastante fijada. En concreto, constatamos que se trata de una estructura bipartita, con un área superior preformateada, la denominada cabecera, y un área inferior, destinada al texto o mensaje, más conocida como cuerpo.

9 Para Montesi (2008: 552), las nuevas formas de comunicación mediatizadas por ordenador (CMO) son fruto, esencialmente, de las funciones que el nuevo medio ofrece, esto es, la posibilidad de búsqueda, la navegación y la interactividad.

10 Sobre la transformación de los géneros tradicionales en Internet y el nacimiento de nuevos géneros en la CMO, véase Shephred y Watters (1998: 97-109).

${ }^{11}$ El uso de las herramientas que el nuevo formato le ofrece ha desencadenado que el boletín digital o newsletter no tenga ya casi nada que ver con el boletín en papel. De hecho, Miller (1984) «defiende que los géneros "crecen, evolucionan y desaparecen" como respuesta a los fenómenos socioculturales que se van produciendo en los contextos que le son propios» (citado en Ezpeleta, 2004: 141). 


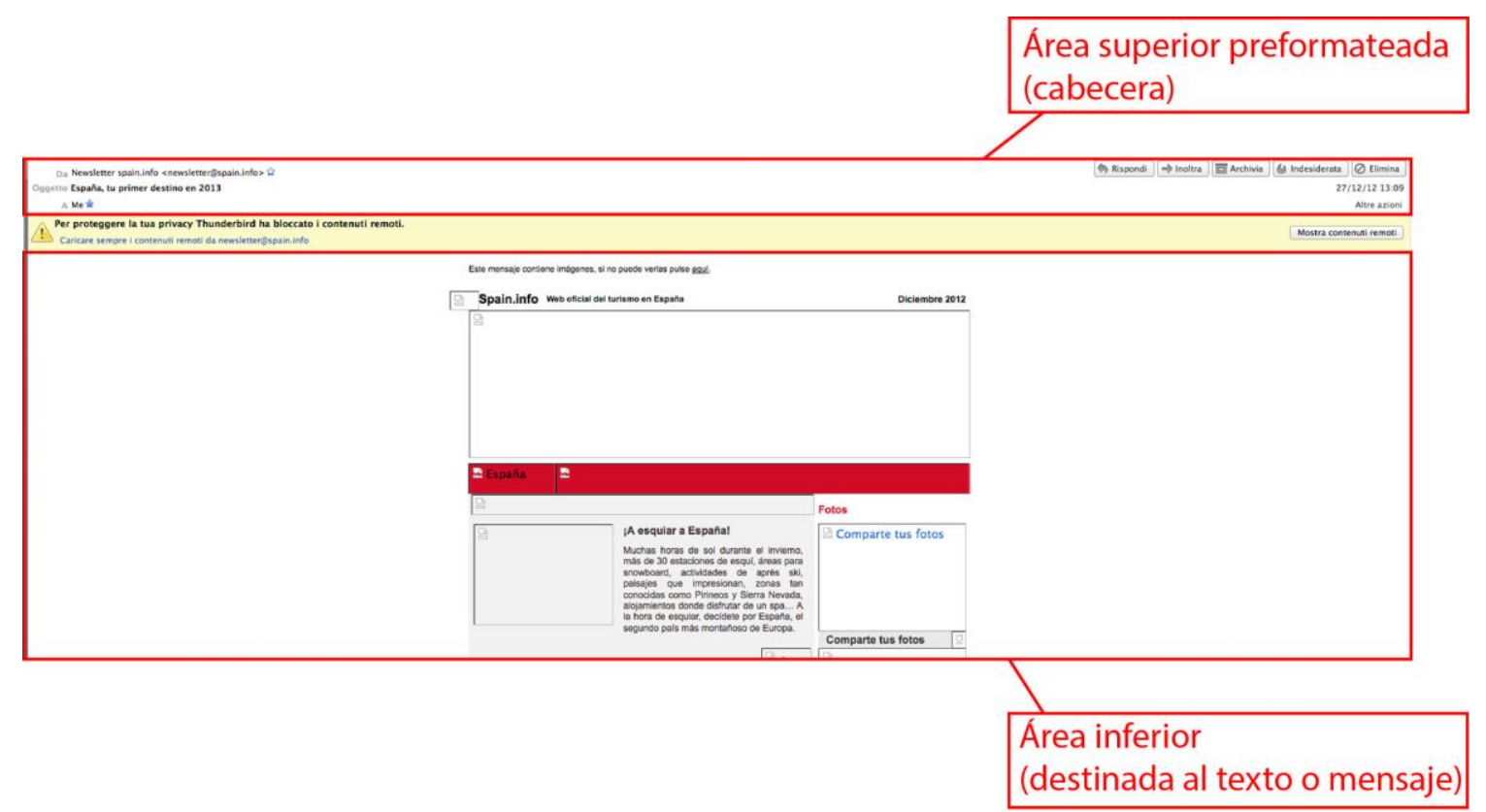

Fig. 1 Boletín digital de Spain.info (Diciembre 2012)

En el lado izquierdo de la cabecera encontramos tres elementos preceptivos: la dirección electrónica desde la que se ha enviado el mensaje $(D e)$, una breve descripción del tema del boletín (Asunto) y la dirección a la que se envía el mensaje (Para). En el lado derecho, dependiendo del sistema de correo, podemos encontrar las opciones: Responder, Reenviar, Archivar, Borrar, Marcar como correo no deseado, Mover a carpeta o Añadir etiquetas, y también la fecha y hora en que ha sido enviado el mensaje (Enviado). En realidad, por lo que se refiere a la cabecera, el ámbito de variantes es casi nulo, pues mucha de la información viene impuesta por el software.

En la cabecera, sin duda el elemento que más atrae la atención del receptor, junto con el nombre del remitente, es el asunto del boletín. Ciertamente, este es el elemento clave que nos inducirá a visualizar o no la newsletter. Por lo tanto, del lenguaje que se utilice en la línea Asunto y de su capacidad para suscitar el interés del usuario dependerá en buena medida la apertura del boletín. En este sentido, los expertos en comunicación en Internet recomiendan que la descripción del asunto se atenga a las máximas de claridad, brevedad, relevancia y concreción ${ }^{12}$. A menudo, dependiendo del sistema de correo, puede aparecer también entre el bloque superior (cabecera) e inferior (cuerpo) un bloque horizontal de color amarillo con la señal de advertencia de peligro. En realidad, se trata de un aviso del sistema de correo que nos está preguntando explícitamente si queremos visualizar el contenido del cuerpo del boletín. Se trata,

${ }^{12}$ En líneas generales, los criterios que se aconsejan seguir para la descripción del Asunto en la cabecera de las newsletters son, en buena medida, los mismos que para la línea Asunto del género correo electronico (Crystal, 2002: 117), esto es, se recomienda atenerse a las máximas conversacionales de Grice (1975). No obstante, las peculiares características del boletín digital de promoción turística determinan que esta línea adquiera especial relevancia en este tipo de boletines. 
obviamente, de una ulterior medida de seguridad del sistema para evitar los tan molestos correos basura.

En el cuerpo identificamos también una serie de elementos obligatorios y otros opcionales. En primer lugar, visto que normalmente las newsletters se envían en formato html y, además, suelen contener imágenes y enlaces al sitio o portal del emisor, dependiendo siempre del sistema, puede ser necesario pinchar en un enlace de acceso para ver los contenidos. En consecuencia, en la parte superior de los boletines encontraremos siempre una frase tipo Este mensaje contiene imágenes, si no puede verlas pulse aquí. Pinchando donde se nos indica, podremos visualizar todos los contenidos del boletín que el sistema había bloqueado.

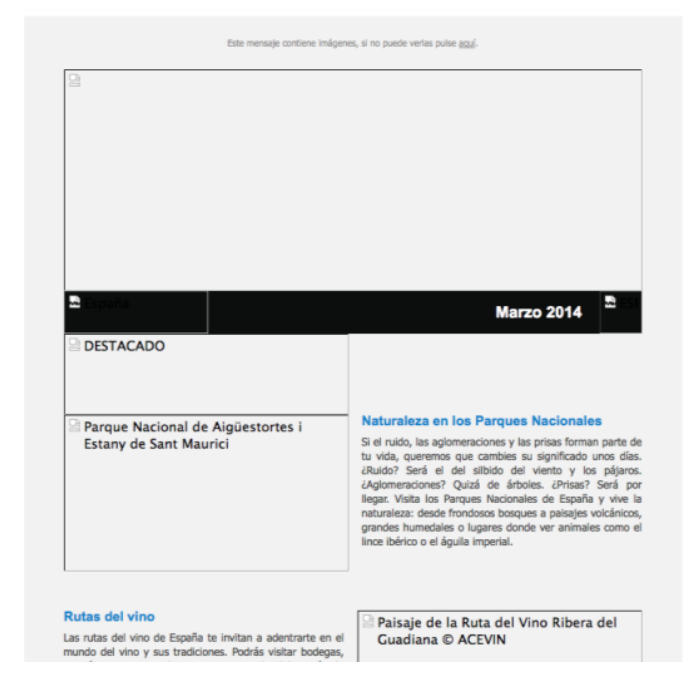

Fig. 2 Cuerpo Newsletter. Marzo 2014

Otro elemento preceptivo es el pie de página, donde normalmente se recogen datos sobre el emisor, la normativa y el derecho del usuario a darse de baja. En realidad, por imposición legal, hay que ofrecer siempre al usuario la posibilidad de darse de baja en cualquier momento. Aparte estos dos elementos canónicos, por lo demás, el cuerpo de las newsletter presenta una gama muy variada de combinaciones de bloques horizontales o verticales de diferentes tipos, tamaños, colores, etc.

\section{DESCRIPCIÓN Y ANÁLISIS DE LA NEWSLETTER DE SPAIN.INFO}

En el caso que nos ocupa, Newsletter spain.info, el contexto sociocultural impone que el usuario se inscriba previamente de forma voluntaria al boletín electrónico, con lo que da así su autorización a recibirlo en su buzón. Para ello, normalmente, tendrá que acceder al portal o sitio del emisor. En nuestro caso concreto, es necesario que entre en la página de inicio de www.spain.info, donde, tras 
pinchar sobre el rótulo Newsletter, se abre en una ventana nueva un formulario que tiene que rellenar si quiere recibir el boletín ${ }^{13}$.

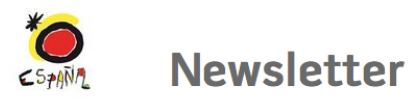

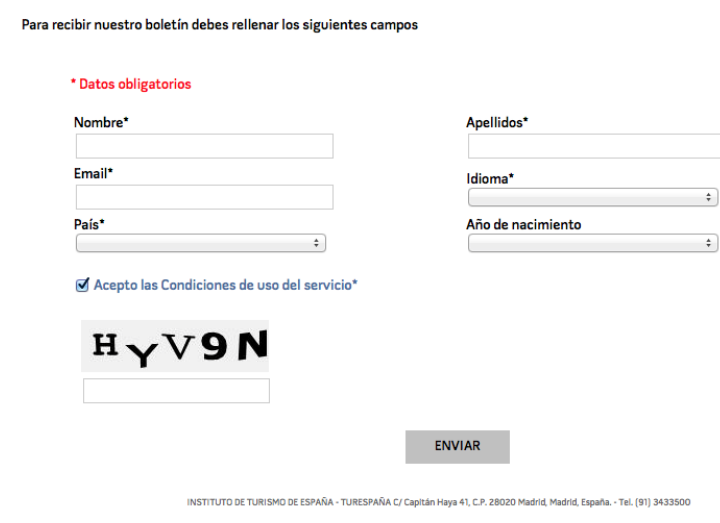

Fig. 3 Formulario boletín Spain.info

Los datos que se solicitan al usuario son edad anagráfica, género y país de origen, esto es, se basan exclusivamente en criterios sociodemográficos. De acuerdo con García López (2001: 137), consideramos que la segmentación y los perfiles elaborados a través de las variables tradicionales -ocupación, sexo, edad y hábitat- «apenas dan cuenta ya de los deseos y comportamientos de una sociedad más flexible y porosa» ${ }^{14}$. Desde

${ }^{13}$ En este formulario los campos presentes permiten identificar solo tres datos del usuario: el país de origen, la edad anagráfica y el género. En cambio, en el nuevo portal www.spain.info se ha creado una sección basada en la segmentación, donde el usuario selecciona su perfil (joven, familia, senior, LGTB, etc.) y el interés que motiva su viaje a España (naturaleza, deporte, playa, gastronomía, etc.) y a partir de ahí la web le ofrece distintas posibilidades de viajar a España vinculadas con sus preferencias. Una segmentación muy parecida a la del portal español la encontramos también, por ejemplo, en el formulario de inscripción que hay que rellenar para recibir la newsletter del portal turístico francés (http://es.rendezvousenfrance.com). En el caso francés, la segmentación se basa en el eje geográfico de interés, tipología de turismo, tipo de alojamiento, etc. Además, el portal francés en su página de inicio, bajo el rótulo Archivo newsletter, permite que cualquier navegante pueda consultar los últimos boletines de noticias. Por el contrario, en el caso español, la única posibilidad de acceder al contenido de la newsletter es inscribiéndose al boletín.

${ }^{14}$ De hecho, García López (2001: 137-138) pone de relieve también que ya en 1992 Costa apuntaba que «si los años 80 fueron años del yo, del individualismo egoísta -que no ambicionaba más allá del éxito y de la satisfacción personal- los 90 quieren compañía. Al entorno familiar se suma el de las amistades y, estimulados por la crisis económica, retornan los valores y principios básicos: la búsqueda de la felicidad ya no pasa por la acumulación de bienes sino por los placeres de las pequeñas cosas importantes; es la comodidad antes que la ostentación, se prefiere el paseo antes que la 
nuestro punto de vista, como pone de relieve también el mismo autor $(2001,138)$, se impone una nueva segmentación que tenga en cuenta además los «estilos de vida», esto es, que combine los criterios sociodemográficos con los «socio-culturales».

Por otra parte, al rellenar y enviar el formulario, el usuario acepta las Condiciones de uso del servicio impuestas por el emisor. Aunque al receptor, como ya hemos señalado, se le reconoce el derecho a darse de baja en cualquier momento del servicio previamente solicitado ${ }^{15}$. Por tanto, nos hallamos ante un género institucional totalmente permisivo. Ciertamente, el usuario que se suscribe a esta newsletter lo hace porque está muy interesado en los posibles contenidos que esta le puede proporcionar.

La macroestructura de la newsletter de Spain.info presenta, como ya hemos señalado, una estructura bipartita; se trata de un esquema organizativo muy ritualizado con un área superior o cabecera y una zona inferior o cuerpo. Por lo que se refiere al cuerpo de nuestro boletín, este refleja un esquema organizativo muy similar al que mostraba la página de inicio del portal Spain.info antes de ser modificada en junio de $2013^{16}$.

\section{CARACTERIZACIÓN INTRATEXTUAL}

Como señalábamos en el tercer apartado, en este género textual el enunciado de la línea Asunto adquiere especial relevancia. Por consiguiente, en este género discursivo la frase de esta línea se suele erigir en el hilo, o cuanto menos en uno de los hilos temáticos que se desarrollará en el cuerpo. Esto es, el texto del cuerpo temáticamente suele estár total o parcialmente supeditado al contenido del Asunto del bloque superior. Obsérvense, en este sentido, los temas presentes en nuestro corpus de estudio:

$\begin{array}{lll}\text { De } & \text { Asunto } & \text { Enviado } \\ \text { Spain Info } & \text { ¿Quieres disfrutar? Ven a España } & 24 / 04 / 2012 \\ \text { Spain Info } & \text { Ya puedes disfrutar del mar } & 22 / 05 / 2012 \\ \text { Spain Info } & \text { ¿Necesitas desconectar? Ven a España } & 14 / 06 / 2012 \\ \text { Spain Info } & \text { Este verano, ven de vacaciones a España } & 05 / 07 / 2012 \\ \text { Spain Info } & \text { Ven y disfruta España } & 16 / 08 / 2012 \\ \text { Newsletter spain.info } & \text { Un otoño lleno de luz, conoce España } & 23 / 09 / 2012 \\ \text { Newsletter spain.info } & \text { Olvida el estrés } & 17 / 10 / 2012\end{array}$

velocidad, lo natural a lo diseñado. Es en esta transformación que crece la conciencia y se abre la curiosidad por otros modos de vida [...] y formas distintas de viajar -como el ecoturismo-».

15 Véase el asterisco Condiciones de uso del servicio en el formulario de inscripción: «los usuarios podrán revocar en cualquier momento el consentimiento otorgado, haciendo click aquí».

${ }^{16}$ Esto es, cabecera, cuerpo y pie de página. Sobre las características de la macroestructura del portal Spain.info, véase Rodríguez Abella (2013: 222-226). 
Newsletter spain.info

Newsletter spain.info

Newsletter spain.info

Newsletter spain.info

Newsletter spain.info

Newsletter spain.info

Newsletter spain.info

Newsletter spain.info

Newsletter spain.info

Newsletter spain.info

Newsletter spain.info

Newsletter spain.info

Newsletter spain.info

Newsletter spain.info

Newsletter spain.info

Newsletter spain.info

Newsletter spain.info

Newsletter spain.info

Newsletter spain.info

Newsletter spain.info
Descubre nuestro interior

$15 / 11 / 2012$

Disfruta de la Navidad en España

$11 / 12 / 2012$

España, tu primer destino en 2013

$27 / 12 / 2012$

Comienza el año cuidándote

$17 / 01 / 2013$

Naturaleza y Cultura en España

$21 / 02 / 2013$

Esta primavera ven a España

Naturaleza, Patrimonio de la Humanidad

$14 / 03 / 2013$

$16 / 04 / 2013$

Vive una nueva experiencia en España

$16 / 05 / 2013$

Descubre el Nuevo Spain.info

$27 / 06 / 2013$

Ven a España

$16 / 07 / 2013$

Mis vacaciones en España

$25 / 07 / 2013$

Este otoño conoce España

$17 / 09 / 2014$

España, destino accesible

$15 / 10 / 2013$

$07 / 11 / 2013$

$26 / 11 / 2013$

Descubre lo que te ofrece España

Descubre las Ciudades Patrimonio de la Humanidad de España

Disfruta de los últimos días del año en España

$19 / 12 / 2013$

Este invierno ven a España

$30 / 01 / 2014$

Te proponemos un plan

$20 / 02 / 2014$

En marzo, saborea España

$13 / 03 / 2014$

Fig. 4. Remitente, asunto y fecha de envío de las últimas 27 newsletters de Spain.info

En el gráfico (fig. 4) se refleja, por una parte, la frecuencia de la newsletter, grosso modo, mensual; por otra, cómo el emisor, en un breve arco de tiempo (unos dos años), opta por variar la denominación de la dirección electrónica desde la que se envía el mensaje. Así, si en las cinco primeras newsletters la dirección remitía al portal institucional del Estado, a partir de la newsletter del 23/09/2013 se opta por resaltar el género de pertenencia (newsletter) y, a continuación, se indican los datos de quien emite el boletín, Spain.info. Este hecho viene a corroborar la flexibilidad y versatilidad de los géneros para adaptarse a las exigencias de las diferentes situaciones comunicativas. Efectivamente, esta práctica permite, además, distinguir el género newsletter del género/canal correo electronico.

Desde un punto de vista lingüístico, como suele ser ya habitual en la promoción turística institucional ${ }^{17}$, comprobamos que se interpela directamente al receptor

\footnotetext{
${ }^{17}$ Sobre el tuteo en el ámbito del turismo, véase Rodríguez Abella (2013).
} 
mediante el uso de imperativos, estructuras interrogativas, el tuteo, etc. Por lo que se refiere al tratamiento que el enunciador dispensa al enunciatario, se constata un uso generalizado del pronombre de segunda persona. De hecho, la selección del pronombre tú se ha convertido en una estrategia socialmente ya asumida en este género discursivo ${ }^{18}$. Por otra parte, no cabe duda de que este recurso lingüístico posibilita el estrechamiento de la distancia interpersonal (Blas Arroyo, 2005: 20) ${ }^{19}$, con lo que se proporciona proximidad entre el emisor y el receptor.

Con todo, como se puede comprobar en la línea Asunto de nuestro corpus, el pronombre personal de segunda persona de singular tú no aparece verbalizado. De hecho, en los enunciados que acabamos de presentar, la segunda persona aparece marcada solo en las formas conjugadas del verbo gracias a los morfemas flexivos de persona y número, que como es sabido son los que contienen el valor deíctico (1) y (2), y a través de pronombres átonos y posesivos (2) y (3):

(1) ¿Necesitas desconectar? Ven a España.

(2) Comienza el año cuidándote.

(3) España, tu primer destino en 2013.

En la tabla (fig. 4) se confirma también otra práctica lingüística característica del género promocional, esto es, el uso ya fosilizado de la apelación directa como esquema suasorio. En particular, comprobamos que de los veintisiete enunciados que forman nuestro corpus, en diecinueve el mensaje principal se apoya en una llamada directa ejercida desde el texto sobre el receptor. En concreto, la exhortación se actualiza a través de imperativos en segunda persona del singular, en función apelativa directa, como en los ejemplos (4), (5) y (6):

(4) Olvida el estrés.

(5) Descubre nuestro interior.

(6) Disfruta de la Navidad en España.

Sobre el imperativo, hay acuerdo general en que este constituye la marca por excelencia del discurso persuasivo, puesto que la interpelación directa permite «recabar la atención de nuestro interlocutor, dirigir el ejercicio de su entendimiento, voluntad o sentidos hacia referencias conocidas o desconocidas, pasadas o futuras» (Giménez Resano, 1977: 3) ${ }^{20}$. Como apunta Giménez Resano (1977, 3), la forma imperativa no comporta necesariamente una orden estricta, es más, a menudo, su significado se desliza

18 De acuerdo con Blas Arroyo (2005: 26), consideramos que «los empleos de tú o usted responden, las más de las veces, a formas de actuar ritualizadas, o a [...] un comportamiento verbal socialmente aceptable dentro de las coordenada sociales y comunicativas correspondientes».

19 Por lo que se refiere al uso de los pronombres de tratamiento en los textos turísticos de promoción institucional, constatamos que, en líneas generales, se ha impuesto el tratamiento no marcado a base de tú.

${ }^{20}$ En líneas genrales, y de acuerdo con Garrido Medina (1999: 3910), consideramos que las dos propiedades más destacadas del imperativo son su referencia a acciones futuras y el hecho de dirigirse al oyente. 
hacia una invitación complaciente, un permiso amable ${ }^{21}$. Efectivamente, en ámbito promocional, el empleo del imperativo permite sobre todo «llamar la atención y enganchar al lector» (Escribano, 2006: 284). Por consiguiente, su uso «tiene más que ver con la capacidad apelativa del lenguaje que con la orden o la exigencia» (Escribano, 2006: 285). Con todo, como ya hemos señalado, en nuestro caso los enunciados imperativos son la fórmula sintáctica privilegiada en la línea gancho del Asunto. Es más, once enunciados empiezan con un imperativo:

(7) Ven y disfruta España.

(8) Descubre lo que te ofrece España.

(9) Vive una nueva experiencia en España.

En algunos casos, como en la frase número (7), el sentido final del enunciado imperativo parece responder al par condición-consecuencia. Es decir, si realizamos el desplazamiento que se nos sugiere (ir a España), este se verá recompensado con un estado o reacción emocional positiva (disfrutar). Por consiguiente, el emisor justifica la exhortación, ven, mediante el operador argumentativo disfrutar. Muy parecida resulta también la estrategia utilizada en la primera newsletter de nuestro corpus:

(10) ¿Quieres disfrutar? Ven a España.

En este caso (10), para establecer contacto con el receptor, se recurre a una estructura interrogativa total (¿Quieres disfrutar?) ${ }^{22}$. Indudablemente, desde el punto de vista discursivo, esta pregunta funciona como un operador argumentativo orientado hacia una respuesta afirmativa. La aserción implícita sirve también de garantía para hacer admitir una conclusión, expresada en este enunciado mediante un imperativo (Ven a España $)^{23}$. Ilocutivamente, interpretamos este imperativo como consejo o sugerencia. Así pues, constatamos que también en este enunciado la argumentación se basa en el estado que nos causará el desplazamiento propuesto. Por otra parte, tanto en esta cláusula (10) como en (7), (8) y (9), nos hallamos ante actos de habla directivos no impositivos. Esto es, se presentan como una invitación que comporta o sugiere una promesa positiva para el receptor ${ }^{24}$. Por lo que se refiere al resto de enunciados de nuestro corpus, solo en dos casos -(11) y (12)- se recurre al uso del presente de indicativo:

${ }^{21}$ En opinion de Escribano (2006: 284), a menudo se trata de un mandato que «tiene más que ver con la invitación que con la orden».

${ }^{22}$ Como apunta Sánchez Corral (1991: 197-198), no cabe duda de que el emisor, al seleccionar la estructura interrogativa, además de la función de llamada al receptor, el efecto persuasivo que busca es también el de crear la ilusión dialógica.

${ }^{23}$ Esta misma estrategia se utiliza también en la tercera newsletter de nuestro corpus: ¿Necesitas desconectar? Ven a España.

${ }^{24}$ De acuerdo con Mulder (1998: 264), en virtud de que el beneficiario ultimo de la acción sea el emisor o el receptor, podemos distinguir entre actos directivos impositivos y no impositivos. Así, desde la perspectiva del emisor, si la acción que se expresa en el directivo beneficia al receptor nos hallamos ante un directivo no impositivo. 
(11) Ya puedes disfrutar del mar.

(12) Te proponemos un plan.

En el primer ejemplo, (11), el adverbio de tiempo ya al inicio del enunciado precede al verbo poder en segunda persona de singular, y aporta a la oración un matiz expresivo de esperanza, de promesa. En concreto, el contenido presupuesto es que durante un tiempo no se ha podido disfrutar del mar, pero ahora ha llegado el momento para poder hacerlo. En el plano de lo temporal, por tanto, se intenta hacer coincidir el proceso en potencia, disfrutar, proceso donde se apela al ámbito de las sensaciones, con el presente, con el ahora, del receptor. En el segundo caso, (12), se recurre a la primera persona de plural del presente de indicativo para involucrar al receptor y generar empatía.

En los demás enunciados, como se puede comprobar en los ejemplos (13), (14), (15), (16), (17) y (18) extraídos de nuestro corpus, se opta por frases nominales que destacan fundamentalmente algún aspecto específico del destino España -(14), (15), (16) y (17) - o bien presentan alguna oferta acorde con el periodo del año -(13) y (18)-:

(13) España, tu primer destino en 2013.

(14) Naturaleza y Cultura en España.

(15) Naturaleza, Patrimonio de la Humanidad.

(16) Mis vacaciones en España.

(17) España, destino accesible.

(18) Propuestas de viaje para Otoño.

Como apunta Navas Ruiz (1977: 131), la frase nominal aparece abundamente en castellano; es más, constituye «un hecho gramatical normal con un puesto muy concreto y determinado en la economía y estructura de la lengua ${ }^{25}$. Por ejemplo, en la construcción condensada (15), el término en aposición, Patrimonio de la Humanidad, tiene carácter identificativo. Por tanto, el emisor mediante este procedimiento evidencia la característica o propiedad que considera más significativa del antecedente Naturaleza $a^{26}$. De hecho, el recurso a la paráfrasis nominal en aposición bimembre es muy frecuente en el ámbito promocional porque permite al locutor plasmar el aspecto que desea evidenciar ante el receptor. También en (13) y (17) la aposición presenta un esquema sintagmático bimembre; además, en (17), la paráfrasis nominal presenta un marcado valor connotativo. En (14), (16) y (18), por el contrario, nos hallamos ante enunciados con esquemas sintagmáticos unimembres. Se trata de actos ilocucionarios, donde el (14) y el (16) son de tipo representativo, mientras que en la frase con base no verbal número (18) nos hallamos ante un acto de habla indirecto de tipo persuasivo.

Otro mecanismo característico del ámbito turístico es la «polarización sobre el emisor» del mensaje (Febas Borra, 1978: 34). En efecto, en nuestro corpus

\footnotetext{
${ }^{25}$ Un estudio pormenorizado de las estructuras predicativas de verbo ausente se puede ver en Gutiérrez Ordóñez (1997: 66-89).

${ }^{26}$ Para un análisis detallado de la aposición y otras relaciones de predicación en el sintagma nominal, véase Suñer Gratacós (1999: 523-564).
} 
contabilizamos la presencia del autorreferente España en diecinueve enunciados -(1), (3), (6), (7), (8), (9), (10), (13), (14), (16), (17), (19), (20), (21), (22), (23), etc.-, mientras que el también autorreferencial Spain.info aparece en una cláusula -(24)-.

(19) Este invierno ven a España.

(20) Este verano, ven de vacaciones a España.

(21) Este primavera ven a España.

(22) Ven a España.

(23) En marzo, saborea España.

(24) Descubre el nuevo Spain.info.

Por último, por lo que se refiere a la interpelación directa, cabe señalar que en estas construcciones constatamos que el verbo que presenta mayor frecuencia de uso es el verbo de movimiento venir, que encontramos en siete cláusulas ${ }^{27}$, verbo que, como apunta Sbisà (2007: 59), implica «un avvicinamento rispetto al centro deittico» ${ }^{28}$. A continuación, en orden de frecuencia, aparecen los verbos disfrutar y descubrir, respectivamente, cuatro veces; el verbo conocer, en dos enunciados y, por último, los verbos olvidar, comenzar, vivir y saborear, que registramos una sola vez. La fuerza implicativa se apoya, por tanto, preferentemente, en verbos que exhortan, invitan o aconsejan al receptor a realizar determinadas acciones. El efecto perlocutivo de esta estrategia lingüística es evidente.

\section{A MODO DE CONCLUSIÓN}

La recopilación y análisis de nuestro corpus de trabajo, los últimos 27 boletines digitales de Spain.info, nos ha permitido detectar un marcador autorreferencial que expresa de forma explícita la identidad genérica de los textos objeto de estudio ${ }^{29}$. Efectivamente, comprobamos que a partir del 23/09/2012 se coloca una etiqueta genérica situada en la cabecera del boletín, en concreto, después del remitente. Esta etiqueta desempeña el papel de marcador de género y nos permite categorizar los textos recopilados en términos genéricos como pertenecientes al cibergénero newsletter ${ }^{30}$. Asimismo, si tenemos en cuenta la taxonomía de géneros cibernéticos de Shepherd y Watters (1998: 98), podemos encuadrar la newsletter como un género nuevo y

27 En nuestro corpus de estudio, como ya hemos evidenciado, la interpelación se plasma fudamentalmente por medio de frases imperativas.

28 Sbisà (2007: 59) evidencia cómo «numerosi elementi lessicali, sopratutto verbi, ma anche sostantivi o avverbi, attivano pressupposizioni in quanto è soltanto a determinate condizioni che il loro uso risulta appropiato. Fra questi vi sono elementi lessicali che si riferiscono a eventi o azioni che possono aver luogo soltanto a partire de uno stato precedente di un determinato tipo. Così, i verbi di cambiamento di stato come "cominciare", "continuare", "smettere", danno per scontato che ciò di cui si parla abbia presentato precedentemente un certo stato».

${ }^{29}$ Sobre identidad genérica y mezclas de géneros, véase Miranda (2012).

30 Para un análisis más detallado sobre los marcadores de los parámetros genéricos, tanto autorreferenciales como inferenciales, véase Miranda (2012: 206-207). 
emergente de Internet, cuyo propósito comunicativo principal es informar y persuadir a los suscriptores con nuevas propuestas, ofertas, etc.

Por otra parte, queda claro también que en este género discursivo la fórmula inaugural de la línea Asunto cumple la función de titular o gancho para atrapar y estimular al receptor de la newsletter a abrir el boletín ${ }^{31}$. En consecuencia, la función discursiva dominante en los textos de la línea Asunto es la apelativa. Por consiguiente, inicialmente, en el género newsletter, el proceso de persuasión es básicamente linguiístico. Además, como hemos podido constatar en nuestro corpus de estudio, el intento de establecer contacto con el receptor se canaliza principalmente a través de estructuras imperativas, frases nominales y oraciones interrogativas.

Cabe señalar también que, aunque nuestro seguimiento alcanza apenas los dos años, los recursos lingüísticos utilizados para ponderar el destino España en la línea Asunto son, desde nuestro punto de vista, algo repetitivos ${ }^{32}$. Consideramos que es fundamental prestar mucha atención a los enunciados de esta línea, porque, como ya hemos señalado, el éxito o fracaso del boletín depende, en buena medida, de la capacidad de «impresionar al receptor y ganarlo a la causa del emisor» (López Eire, 1998: 19), para lograr, evidentemente, que abra el boletín.

Por lo que se refiere al contenido semántico-pragmático de los enunciados objeto de estudio, hemos comprobado que este gira fundamentalmente en torno a la promesa de que si visitan España podrán gozar de los aspectos más positivos de la vida. No obstante, como ya hemos señalado anteriormente, sería aconsejable una mayor segmentación de los posibles receptores que tuviera en cuenta sus principales rasgos distintivos, motivaciones, cultura, clase social, etc. Porque, como subraya Ana Bru (citado en Saile, 2013: 35) «los viajeros son cada vez más exigentes y les importa menos el destino y mucho más la experiencia que van a disfrutar o la gente que pueden llegar a conocer» ${ }^{33}$. De hecho, según el escritor suizo Alain de Botton (2013: 7),

l'industria dei viaggi del futuro sarà quella che ci aiuterà a inserirci nella realtà di ogni paese e a capirle. Ci toglierà dalla routine dei musei e ci getterà nella vibrante realtà delle cucine, degli uffici, degli asili e delle feste di matrimonio. Si impara di più della cultura dei Paesi Bassi pranzando con cinque chimici di Amsterdam che non passando le giornate al Rijksmuseum ${ }^{34}$.

${ }^{31}$ En realidad, el enunciado de la línea Asunto se erige en el elemento peritextual más importante en este género discursivo; su importancia y función, hasta cierto punto, es equiparable a la que cumple el título de cualquier obra literaria.

${ }^{32}$ Véanse, por ejemplo, los enunciados, (1) y (10), (5) y (8), etc.

${ }^{33}$ También para Greg Richards, profesor de la Universidad de Tilburg que lleva años estudiando el turismo creativo, «las vacaciones ya no son un mero paréntesis para el descanso, se han convertido en espacios para el aprendizaje y el desarrollo personal» (citado en Saile, 2013: 34).

${ }^{34}$ Como apunta Saile (2013: 35), «el llamado turismo creativo existe desde hace años. En 2004 la Unesco ya creó una red de ciudades creativas cuyos miembros definieron este fenómeno como la tercera generación turística, después del sol y playa y del turismo cultural centrado en museos y rutas monumentales. La esencia de esta nueva manera de viajar es la inmersión en la cultura viva del lugar que se visita. Siempre estuvo al alcance de los viajeros más sofisticados, pero hasta hace poco la oferta disponible era demasiado escasa como para permitir que se popularizase». 
En definitiva, es evidente que los turistas 2.0 desean viajar sin sentirse turistas. En consecuencia, también en este sector se impone un cierto personalismo en el discurso o, por lo menos, un marketing de nichos. Desafortunadamente, en nuestra opinión, Spain.info no está aprovechando por el momento muchas de las potencialidades que le brinda el género newsletter para satisfacer esta demanda.

\section{REFERENCIAS BIBLIOGRÁFICAS}

ARAMBERRI, Julio (2011): Turismo de masas y modernidad. Un enfoque sociológico, Madrid, CIS.

BlAS ARROYO, José Luis (2005): «Los grados de la cortesía verbal: reflexiones en torno a algunas estrategias y recursos lingüísticos en el español peninsular contemporáneo», RILI (Revista Internacional de Lingüística Iberoamericana), Madrid, Iberoamericana Editorial/Vervuert, 9-29.

BotTon, Alain (2013): «Una generazione curiosa», Internazionale, 2 de agosto de 2013, 7.

CALvi, Maria Vittoria (2009): «El lenguaje del turismo», en Calvi, Maria Vittoria, Cristina Bordonaba Zabalza, Giovanna Mapelli y Javier Santos López, eds., Las lenguas de especialidad en español, Roma, Carocci, 199-224.

CALVI, Maria Vittoria (2010): «Los géneros discursivos en la lengua del turismo: una propuesta de clasificación» en Ibérica, 19, 9-32 [en línea]: $<$ http://www.aelfe.org/documents/01_19_Calvi.pdf $>$. [Consulta: 06/12/ 2013].

CRYSTAL, David (2002): El lenguaje e Internet, Madrid, Cambridge University Press.

CRYSTAL, David (2005): La revolución del lenguaje, Madrid, Alianza Editorial.

De Borja, Luis, Josep Andreu, Casanovas Pla y Ramón Bosch Camprubí (2002): El consumidor turístico, Madrid, ESIC Editorial.

ESCRIBANO HERNÁNDEZ, Asunción (2006): «La cortesía lingüística como recurso publicitario», Zer, 20, 271-297 [en línea]: 〈http://www.ehu.es/zer/>. [Consulta: 09/01/2014].

EZPELETA PIORNO, Pilar (2005): «La noción de género en la planificación de la docencia de la traducción de la primera lengua extranjera», en García Izquierdo, Isabel, ed., El género textual y la traducción. Reflexiones teóricas y aplicaciones pedagógicas, Bern, Peter Lang.

FEBAS BORRA, José Luis (1978): «Semiología del lenguaje turístico (Investigación sobre los folletos españoles de turismo)», Estudios turísticos, 57-58, 17-204.

GARCÍA LóPEZ, Marcial (2001): Publicidad Institucional: el Estado Anunciante, Málaga, Universidad de Málaga.

GARRIDo Medina, Joaquín César (1999): «Los actos de habla. Las oraciones imperativas», en Bosque, Ignacio y Violeta Demonte, coords., Gramática descriptiva de la lengua española, vol. 3 (Entre la oración y el discurso. Morfología), Madrid, Espasa Calpe, 3879-3928. 
GILTROw, Janet y Dieter STEIN (2009): Genres in the Internet: issues in the theory of genre, Ámsterdam, John Benjamins.

GiMÉnEZ RESANO, Gaudioso (1977): «Notas sobre el imperativo del verbo español» Cuadernos de investigación filológica, 3, 3-18 [en línea]: <http://dialnet.unirioja.es/servlet/articulo?codigo=68879>. [Consulta: 14/11/2013].

GUTIÉRREZ ORDÓÑEZ, Salvador (1997): La oración y sus funciones, Madrid, Arco libros.

Kotler, Philip, Hermawan Kartajaya e Iwan Setiawan (2013): Marketing 3.0: dal prodotto al cliente, all'anima, Milán, Il sole 24 ORE.

Kotler, Philip, John T. Bowen y James C. MAKens (2010): Marketing del turismo, Milán-Turín, Pearson Italia.

LÓPEZ EIRE, Antonio (1998): La retórica en la publicidad, Madrid, Arco/Libros.

Ministerio De INDUSTRIA, EnERGía y TURISMO (2012-2015): Plan Nacional $e$ Integral de Turismo 2012-2015 [en línea]: <http://www.tourspain.es/eses/VDE/Documentos\%20Vision\%20Destino\%20Espaa/Plan\%20Nacional\%20e\%20Inte gral\%20de\%20Turismo\%202012_2015_FINAL_REVISADO\%20150313.pdf>.

[Consulta: 05/11/ 2013].

MIRANDA, Florencia (2012): «Textos, identidad genérica y mezclas de géneros» en Shiro, Martha, Patrick Charaudeau y Luisa Granato, eds., Los géneros discursivos desde múltiples perspectivas: teorías y análisis, Madrid, Iberoamericana Vervuert, 199-219.

MONTESI, Michela (2008): «Géneros web: líneas de investigación» en $E l$ Profesional de la Informacion 17, n. ${ }^{\circ} \quad 5, \quad 551-558$, <http://dx.doi.org/10.3145/epi.2008.sep.10>.

MuLDER, Gijs (1998): «Un estudio empírico de los actos de habla directivos en español» en Haverkate, Henk, Gijs Mulder y Carolina Fraile Maldonado, eds., La pragmática lingüística del español: recientes desarrollos, Ámsterdam, Rodopi, 237-276.

NAVAS RUIZ, Ricardo (1977): «Pausa, base verbal y grado cero», en Navas Ruiz, Ricardo, Ser y estar. El sistema atributivo del español, Salamanca, Almár, 127-138.

PAOLILlO, John C., Jonathan WARREN y Breanne KUNZ (2010): «Genre Emergence in Amateur Flash», en Mehler, Alexander, Serge Sharoff y Marina Santini, eds., Genres on the Web: Computational Models and Empirical Studies, Heidelberg, Springer, <http://dx.doi.org/10.1007/978-90-481-9178-9_13>.

PINI, Giacomo (2010): Il nuovo marketing del prodotto turistico, Milán, FrancoAngeli.

RoDRíGueZ ABELlA, Rosa María (2013): «El discurso de la promoción turística institucional en Internet», en Chierichetti, Luisa y Giovanni Garofalo, eds., Discurso profesional y lingüística de corpus. Perspectivas de investigación, Bergamo, CELSB, 217-242 [en línea]: 〈http://dinamico.unibg.it/cerlis/public/CERLIS_SERIES_3.pdf>. [Consulta: 09/01/ 2014].

SAILE, Belinda (2013): «Turistas de última generación», El País, 5 de mayo de 2013, 34-35.

SÁNCHEZ CORRAL, Luis (1991): Retórica y sintaxis de la publicidad (itinerarios de la persuasión), Córdoba, Universidad de Córdoba. 
SAnMARTín SÁEZ, Julia, ed. (2012): Discurso turístico e Internet, Madrid, Iberoamericana-Vervuert.

SANTINI, Marina (2007): «Characterizing Genres of Web Pages: Genre Hybridism and Individualization» en Proceeding of the 40th Hawaii International Conference on System Sciences, IEEE-Computer Society, <http://dx.doi.org/10.1109/hicss.2007.124>:

SBISÀ, Marina (2007): Detto non detto. Le forme della comunicazione implicita, Milán, Editori Laterza.

SHEPHERD, Michael y Carolyn WATTERS (1998): «The Evolution of Cybergenres», en Sprague, Ralph, ed., Proceedings of the 31 Annual Hawaii International Conference on System Science, Los Alamitos (CA), IEEE-Computer Society, 97-109, <http://dx.doi.org/10.1109/hicss.1998.651688>.

SHIRO, Martha, Patrick ChARAUdEAU y Luisa GRANATO, eds. (2012): Los géneros discursivos desde múltiples perspectivas: teorías y análisis, Madrid, Iberoamericana Vervuert.

SUAU JIMÉNEZ, Francisca (2012): «El turista 2.0 como receptor de la promoción turística: estrategias lingüísticas e importancia de su estudio» en Pasos 10, n. ${ }^{\circ}$ 4, 143 149 [en línea]: 〈http://www.pasosonline.org/Publicados/10412special/PS0412_14.pdf>. [Consulta: 10/11/2013].

SUÑER GRATACÓs, Avel-lina (1999): «La aposición y otras relaciones de predicación en el sintagma nominal» en Bosque, Ignacio y Violeta Demonte, coords., Gramática descriptiva de la lengua española, vol. 1 (Sintaxis básica de las clases de palabras), Madrid, Espasa Calpe, 523-564.

SitOGRAFÍA (sitios web, consultados entre 20/04/ 2012 y 30/03/2014)

$\langle\underline{\text { http://www.segittur.com }>}$

$\langle$ http://www.spain.info $>$

$\langle$ http://www.tourspain.es $>$

$\langle$ http://www.hosteltur.com $>$ 